\section{O PROFAE EM MINAS GERAIS: O TRABALHO DA AGÊNCIA REGIONAL}

THE PROFAE IN MINAS GERAIS:

THE WORK OF THE REGIONAL AGENCY

\author{
Lélia Maria Madeira ${ }^{1}$ \\ Dalva Cifuentes Gonçalves²
}

Resumo Muitos esforços têm sido empreendidos em todas as regiões do país para se levar a bom termo a concretização da política de qualificação profissional na área da saúde. O Projeto de Profissionalização dos Trabalhadores da Área de Enfermagem (PROFAE) é a expressão maior desse propósito, que teve como características essenciais a descentralização e as parcerias, pelas diferentes regiões do país. Neste relato, realizado pela Agência Regional de Minas Gerais, destacam-se aspectos de sua atuação que contribuíram para significativos avanços, junto a todas as instituições envolvidas na implementação dos cursos de Complementação do Ensino Fundamental (CEF) e de Qualificação Profissional de Auxiliar de Enfermagem (CQP).

Palavras-chave Projeto de Profissionalização dos Trabalhadores da Área de Enfermagem (PROFAE); supervisão, monitoramento e avaliação; qualificação profissional; auxiliar de enfermagem.
Abstract In all Brazilian regions many efforts have been made to put into practice the governmental policy on professional qualifications in the area of health. The Project of Professional Training for Workers in the Area of Nursing (PROFAE) is the highest expression of this objective and has, as its basic characteristics, decentralisation and the establishment of partnerships in the country's various regions. This reporting, prepared by the Regional Agency of Minas Gerais, emphasizes those aspects of PROFAE's activities that - together with all other institutions involved in the implementation of the Basic Level Completion (CEF) and the Professional Qualification of Nurse Assistants (CQP) courses - have contributed to bring about a number of significant advancements.

Key words Professional Training for Workers in the Area of Nursing (PROFAE); supervision, monitoring and assessment; professional qualification; nurse assistant. 


\section{0 reconhecimento necessário}

Relatar uma experiência da Agência Regional de Minas Gerais (AR/MG) não deixa de ser um ato de humildade quando se reconhece que, paralelamente, em todas as regiões do país, milhares de pessoas - entre equipes técnicas, coordenadores e professores - vêm se empenhando ao máximo para o sucesso desse empreendimento que tem sido de suma importância na história da enfermagem e dos serviços de saúde. Ao nos dispormos a relatar fatos que nos pareciam significativos e até mesmo inovadores, sabemos que muitas outras situações constatadas no extenso território nacional foram abordadas e tratadas com criatividade e, sobretudo, objetividade, tendo em vista os propósitos do PROFAE.

A execução de um projeto de formação, de um projeto educativo exige a relação, a tarefa conjunta, o trabalho em equipe e o esforço individual. Seria impossível indicar, neste trabalho, todos aqueles com os quais a Agência Regional se articulou, compartilhou e trabalhou e que tiveram um papel de grande significado ao longo do processo desenvolvido de janeiro de 2001 a fevereiro de 2002. Tal fato não nos impede, no entanto, de agradecer e reconhecer, em todos os níveis de atuação do Projeto, aos que colaboraram conosco na busca de respostas concretas às nossas indagações e aos desafios que foram surgindo ao longo do percurso.

\section{A experiência de supervisão, monitoramento e avaliação do PROFAE em Minas Gerais}

Desde as primeiras reflexões que envolveram os profissionais comprometidos com o Projeto, esteve sempre presente a idéia de que estávamos contribuindo para concretizar a promessa de humanização e competência dos serviços de saúde mediante esforço conjugado de integração saúde-educação. Assim, nosso trabalho buscou esse norte, para o qual deveriam convergir todas as ações, orientadas por três diretrizes principais:

- A execução das propostas político-pedagógicas das instituições executoras deveria ser coerente com uma concepção educativa que efetivamente considerasse os alunos como sujeitos, e não meros objetos do processo educativo. Esperava-se, assim, que os futuros profissionais viessem a atuar como agentes conscientes e competentes, capazes de contribuir na promoção das mudanças necessárias à assistência da enfermagem e à qualidade dos seus serviços. Essa diretriz pressupunha a necessidade de permanente diálogo da Agência Regional com as Operadoras, mediante um contínuo processo de articulação e comunicação que permitisse maior visibilidade da concepção de educação nos processos de ensino-aprendizagem, para identificação de for- 
mas construtivas e interativas de aquisição de saberes, habilidades e competências, necessários à formação do educando como ser humano, cidadão e futuro profissional de enfermagem.

- A supervisão, o monitoramento e a avaliação da implementação do PROFAE deveriam identificar, em todas as oportunidades de contatos com as Operadoras, Executoras, turmas, professores, alunos e coordenadores locais, os fatores e os restritivos da execução das propostas, sem perder de vista as potencialidades emergentes, tanto as de caráter pedagógico quanto as operacionais. Para isso, o aperfeiçoamento da ação supervisora deveria conduzir, a par dos instrumentos e de coletas de dados em fase de elaboração e de adoção, a uma verificação mais aprofundada e abrangente da implementação dos cursos, sob uma abordagem predominantemente qualitativa, ampliada progressivamente, pela qual a percepção dos sujeitos do projeto fosse mais considerada.

- Seriam enfatizados os processos avaliativos interligados às formas pelas quais se daria a aprendizagem, em uma perspectiva diagnóstica e formativa, privilegiando a dimensão qualitativa do processo de aprender, sem, no entanto, nos descuidarmos dos aspectos quantitativos favorecedores da infraestrutura necessária, oferecida pelas instituições como suporte ao trabalho pedagógico.

\section{As principais estratégias}

As diretrizes fixadas serviram como referências para a estruturação de um Plano Geral de Trabalho e planos específicos com diferentes estratégias, ao longo do período previsto nos cronogramas das Operadoras. Pela natureza deste relato, não pretendemos explicitar todas as atividades e técnicas desenvolvidas. No entanto, enfatizamos algumas:

- Encontros com as Operadoras - Além dos encontros promovidos com a interveniência da Coordenação Geral do Projeto (GGP) do Ministério da Saúde, a Agência Regional promoveu com cada Operadora uma reunião especial, dentro dos dois primeiros meses de atuação, para discutir questões surgidas da análise das propostas político-pedagógicas, bem como de sua implementação. Na mesma oportunidade, houve intercâmbio de idéias e sugestões a respeito da supervisão e das vertentes de monitoramento e avaliação. - As ações de supervisão - Como as demais, devem ter ocorrido com as demais equipes de supervisão por todo o país. Realizaram-se mediante diversos procedimentos: entrevistas com coordenadores locais, professores, alunos e, quando necessário, integrantes da comunidade; visitas às turmas durante as aulas; observação do ambiente físico das Executoras e turmas (biblioteca, espaços, equipamentos, salas de aula, material didático); análises 
documentais e outros. As informações obtidas forneceram dados para preenchimento de questionários semi-estruturados, com itens fechados e abertos, de natureza qualitativa e quantitativa. Ao longo do trabalho, as informações qualitativas passaram, progressivamente, a predominar.

- Os questionários - Após o segundo mês de supervisão, aperfeiçoaramse os questionários com os propósitos de comparar os dados coletados com as intenções explicitadas nas propostas pedagógicas das Executoras e de confrontar itens identificados com concepções educativas dominantes com os ideais de formação buscados pelo Projeto. A equipe técnica da Agência Regional levantou primeiramente os componentes básicos, tanto os pedagógicos (conteúdo, metodologia, recursos didáticos, relação professor/aluno, estágio supervisionado e avaliação/recuperação) quanto os de ordem técnico-gerencial (articulações/comunicação e iniciativas de educação continuada para docentes e coordenadores). Para cada componente, foram levantados indicadores, que geraram itens fechados para análise por leitura ótica. Por exemplo, em relação ao componente abordagem do conteúdo, o levantamento de indicadores orientou para a construção de itens como a problematização dos temas debatidos, o relacionamento com a realidade dos alunos e a articulação entre as áreas do conhecimento. O componente professor/alunos gerou itens como o desenvolvimento de trabalho integrado entre alunos e professores e a administração de conflitos mediante busca de formas de superação. Tais questionários foram elaborados com itens fechados e itens abertos que permitiam a livre resposta dos entrevistados sobre aspectos facilitadores e dificultadores do processo ensino-aprendizagem. Os dados coletados pelos supervisores, posteriormente, eram cuidadosamente tabulados e analisados pela equipe técnica, oferecendo uma outra gama de informações que vieram a complementar ou reiterar as informações obtidas através dos itens fechados.

- Campos de estágio - Um procedimento investigativo que mereceu meses de estudos e de esforços foi a realização do diagnóstico de campo de estágio por Operadora. Entendeu-se que a qualidade do processo ensino-aprendizagem deveria ser expressa em todas as etapas, desde a proposta político-pedagógica até a prática do profissional que se pretendia formar. Para esse diagnóstico, objetivou-se, primeiramente, conhecer as condições gerais das instituições de saúde hospitalar e de rede básica utilizadas como campos de estágio pelos alunos do PROFAE/MG. Trabalhou-se arduamente na construção do instrumento de coleta de dados que pudesse caracterizar de forma abrangente, porém real, os diferentes campos de estágio utilizados pelos alunos. A dificuldade de criação nasceu da variedade das realidades, dispersas nos serviços de saúde em todo o estado.

Não se pretendeu, contudo, elaborar um instrumento para tabulação de dados, mas sim um instrumento de fácil leitura com dados supostamente disponíveis nas instituições visitadas e que dessem, ao final de seu preenchi- 
mento, uma idéia geral de cada campo. Os supervisores percorreram todas as regiões do estado onde se localizavam turmas do PROFAE, realizando visitas, entrevistas e observações. O diagnóstico foi, então, realizado em relação a cada Operadora do ponto de vista de instituições hospitalares e da rede básica (natureza jurídica, número de leitos, infra-estrutura, corpo clínico, equipe de enfermagem, distribuição dos alunos segundo a demanda).

Apesar de reconhecermos a necessidade de aperfeiçoamento dessa investigação, constatamos que o procedimento foi bastante positivo, não só para o conhecimento das condições gerais das instituições de saúde utilizadas como campo de estágio, como também para apontar, principalmente, deficiências nas oportunidades de aprendizagem de procedimentos técnicos para algumas turmas. Assim, consideramos que o diagnóstico atendeu ao objetivo proposto pela equipe técnica.

- Estudos qualitativos - Uma das estratégias mais significativas proposta e implementada por esta Agência Regional foi, seguramente, a realização de estudos qualitativos iniciados durante o período de visitas de supervisão, mas que tiveram como maior destaque a realização dos grupos focais (AR /MG, 2000). O estudo qualitativo é uma investigação realizada com o objetivo de compreender um objeto e apreendê-lo em seus aspectos relevantes, com metodologia apropriada ao tratamento dos aspectos que se deseja focalizar. As informações são obtidas por meio de observações, entrevistas individuais, análise documental, estudos de casos e grupos focais, sendo preponderantes os dois últimos.

Segundo a Academia para el desarrollo educativo (Healthcom, 1995), o estudo com grupo focal é rico em dados descritivos, pois parte de um plano aberto e flexível para estudar determinado fenômeno de maneira contextualizada, mediante várias fontes de informação, sendo uma de suas características a de buscar representar os diferentes e, muitas vezes, contraditórios pontos de vista presentes numa situação social.

A decisão pelos grupos focais foi uma decorrência da percepção de necessidade e de expectativas de grupos das Operadoras com as quais fizemos reuniões específicas para discutir as respectivas propostas pedagógicas, como também dos resultados apontados nos relatórios mensais das visitas de supervisão. Algumas razões justificaram a escolha dos grupos focais como a técnica qualitativa a utilizar. Dentre estas, destacam-se os debates e a interação em grupo, a geração de idéias novas e originais, o aprofundamento de idéias na identificação de pontos críticos e a participação de todos nas discussões, entre outras.

Como metodologia do trabalho, após estudos teóricos e discussões da equipe técnica, definiram-se como critérios gerais: a) em cada Operadora, deveria haver um grupo focal de Qualificação Profissional (QP) e um de Complementação do Ensino Fundamental (CEF); b) o grupo deveria ser composto 
de 12 a 15 participantes, no máximo, sendo $60 \%$ de instrutores/professores e $40 \%$ de coordenadores locais, além de um moderador, um observador e um relator da Agência Regional; c) o grupo deveria ser composto por elementos que representassem as diversidades da Operadora, considerando-se as diferentes Executoras, as disciplinas/áreas curriculares e as realidades das turmas centralizadas e descentralizadas.

Essas discussões, que duraram de uma hora e meia ao máximo de duas horas, orientaram-se pelas questões elaboradas pela equipe da Agência Regional: O que é o PROFAE e o que significa no contexto regional? Como está sendo desenvolvido o trabalho na sua região? Como você percebe sua atuação (como coordenador/professor)? Como deve ser o profissional que você está ajudando a formar?

Os participantes foram unânimes em avaliar positivamente a realização e o significado dos grupos focais. Afirmaram também que, além de ser um trabalho bastante esclarecedor, a avaliação serviu como troca de experiências e até como terapia. Da parte da Agência Regional, os grupos focais representaram uma oportunidade ímpar de coleta de dados qualitativos. Ao mesmo tempo, seus resultados foram complementares aos demais coletados por meio de outras técnicas, permitindo à Agência Regional compor com maior clareza o quadro representativo da operacionalização do PROFAE em Minas Gerais.

Na figura 1, pode-se visualizar esquematicamente os aspectos fundamentais que perpassaram as discussões nos grupos focais:

O significado positivo do Programa foi identificado no discurso dos professores/coordenadores locais, expresso sob diferentes perspectivas, como pode ser constatado nos fragmentos de discurso a seguir:

“O curso está ajudando a formar o profissional, não só tecnicamente, mas um profissional ético, com compromisso, com responsabilidade (...) há preocupação com sua formação enquanto pessoa... “

“Eu, como Enfermeira do Hospital, vejo que alguns alunos, no seu setor de trabalho (não todos ainda), já vêm operando mudanças na sua forma de agir: Eles dizem: 'Isto não é assim não, eu aprendi na aula passada'”' (AR/MG, 2001, p. 44).

As discussões dos grupos focais, ocorridas com atores centrais da implementação do curso, permitiram maior visibilidade dos desafios. Entre esses, destacam-se: as dificuldades na organização e realização dos estágios - o que gerou, por parte da Agência Regional, a decisão de realizar o diagnóstico dos campos de estágio; a criação de condições para conhecimento prévio em maior profundidade, da natureza e características do jovem e do adulto trabalhador e, a partir daí, a reorganização de conteúdos, metodologias e formas de avaliação; e a necessidade de investimento maciço e sistemático na capacitação pedagógica dos professores/enfermeiros e dos coordenadores, 
Figura 1

Aspectos abordados nas discussões dos grupos focais - AR/MG - 2001

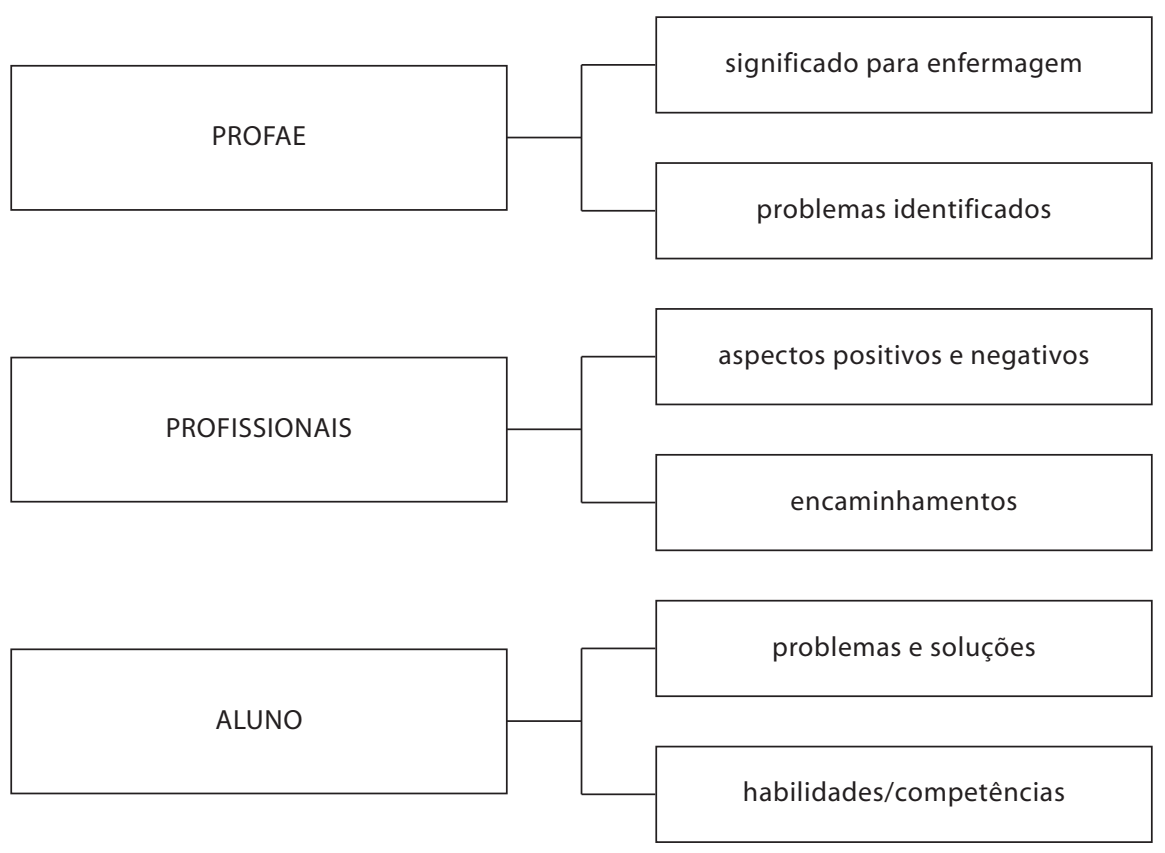

com o envolvimento das próprias Operadoras, da Agência Regional e do Ministério da Saúde.

\section{As perspectivas}

No fechamento do trabalho de 2001, para o relatório final, a Agência Regional realizou uma pesquisa documental objetivando uma análise histórica do progresso de cada Operadora, nas dimensões pedagógicas e gerenciais, tendo como fonte de dados os relatórios de setembro, novembro e dezembro, referentes ao processo de implementação do PROFAE. Descreveu-se, então, esse progresso, elaborando-se ao final, uma síntese do desempenho de cada Operadora e a configuração do seu perfil. O significado dessa medida foi a melhor apreensão não só do grau de preocupação de cada uma com os aspectos substantivos dos processos desenvolvidos em 2001, como também, no que foi possível observar e obter, a percepção de vários indícios da concepção de educação que vem permeando a execução das respectivas propostas pedagógicas (interacionista/construtiva/progressiva ou transmissiva/diretiva/tradicional). 
As informações obtidas e aqui relatadas ofereceram subsídios para o aperfeiçoamento dos nossos trabalhos em 2002, tanto da Agência Regional quanto das Operadoras que prosseguem, além de ajudarem na supervisão, no monitoramento e na avaliação das novas Operadoras.

Ficou claro, também, que todas as Operadoras obtiveram avanços significativos - umas mais, outras menos -, e os resultados indicaram que seus projetos pedagógicos foram, na verdade, construídos e aperfeiçoados ao longo do processo. Nas Operadoras com menores avanços, não se deixou de reconhecer a luta, o esforço para a superação de suas dificuldades e o crescimento duramente alcançado, sob as condições que as cercaram.

\section{Notas}

1 Coordenadora Geral da Agência Regional do Profae em Minas Gerais - Herkenhoff \& Prates Tecnologia e Desenvolvimento. Instituto de Tecnologia e Desenvolvimento de Minas Gerais S/C Ltda. <lelia.bhe@terra.com.br>

2 Coordenadora Pedagógica da Agência Regional do Profae de Minas Gerais Herkenhoff \& Prates Tecnologia e Desenvolvimento.

\section{Referências}

AR/MG (Agência Regional do Profae - Minas Gerais). 2000. Plano de trabalho. Belo Horizonte, 2.

AR/MG(Agência Regional do Profae- Minas Gerais). 2001. Relatório mensal - grupo focal. Belo Horizonte, Dezembro.

HEALTHCOM. 1995. Academia para el desarrollo educativo. El manual para excelencia en la investigación mediante grupos focales. Preparado por Mary Debus. Washington EUA. 